\title{
Política social, paradigma de bem-estar e prática política: análise comparativa de programas de transferências condicionadas
}

\author{
Aloisio Ruscheinsky \\ Universidade do Vale do Rio dos Sinos (Unisinos)
}

\author{
David Martínez Mendizábal
}

Universidad Iberoamericana (UIA)

Política social, paradigma de bem-estar e prática política: análise comparativa de programas de transferências condicionadas

Resumo: A exposição objetiva analisar programas de transferências condicionadas de renda adotados em países como o Brasil e o México, por meio da análise comparativa entre os Programas Bolsa Família e Oportunidades. O problema da pesquisa consiste em examinar a reconfiguração dos sistemas de proteção social por meio da assistência social. Utiliza-se como metodologia uma abordagem a partir da pesquisa documental e da observação empírica. Para apresentar aspectos como parte dos resultados o texto apresenta de forma breve os casos nacionais, para seguir com a abordagem dos impactos sociais diante da pobreza persistente. Diante da gestão social do risco e das vulnerabilidades as políticas em tela garantem um mínimo de segurança em paralelo ao acesso às políticas públicas.

Palavras-chave: Políticas sociais. Desigualdades. Transferência condicionada de renda. Bem-estar.

Social Policy, Paradigm of Well-Being and Political Practice: a comparative analysis of conditional transfer programs

Abstract: This paper analyzes conditional income transfer programs adopted in countries such as Brazil and Mexico, by means of a comparative analysis between the Bolsa Família [Family Grant] and Oportunidades [Opportunities] programs in each country respectively. The research focuses on examining the reconfiguration of the social protection systems through social assistance. The methodology of the study is based on document research and empiric observation. The paper briefly presents these national cases, followed by a look at the social impacts of the persistent poverty in each. Given the social management of risk and of the vulnerabilities, the policies in question guarantee a minimum of security in parallel to access to public policies.

Keywords: Social policies. Inequalities. Conditional income transfer. Well-being. 


\section{Introdução}

Os planos e as estratégias das políticas focais guiadas pela transferência condicionada de recursos monetários para a população pobre foram instaurados em quase todas as nações latino-americanas, porém obedecem às escalas e, por vezes, implicam lógicas políticas diferentes. Em alguns países, se introduziram novas políticas sociais segundo o governo de turno ou continuaram com permuta de nome com ligeiras inovações. Para proceder a uma comparação a respeito de casos nacionais na América Latina de políticas sociais requer um esforço intelectual de compreensão e de síntese. Em nossas investigações temos trabalhado no reconhecimento das especificidades nacionais e sob o problema pesquisa: razões e sintomas que fazem sentido ao estudo comparativo do programa Bolsa Família no Brasil e Oportunidades no México.

O estudo comparativo de políticas sociais compreende o significado, a abrangência e a eficácia, com enfoque na reciprocidade entre condições políticas e econômicas, nas situações de riscos sociais e nas peculiaridades dos arranjos em cada um dos países. A partir das situações específicas, em face da base de dados utilizada em cada país, o estudo comparativo serviu para indagar o funcionamento dos formatos institucionais de distribuição de renda e a variedade de programas sociais traduzidos em mecanismos de legitimidade política para os respectivos governos. Ao abordar semelhanças e diferenças recentes parecem destacar-se a diversificação de programas, o similar desfecho e circunstância política, os instrumentos de avaliação do desempenho e os efeitos potenciais a partir da alteração de indicadores sociais.

A problemática desenvolvida no artigo parte da proposição com sete premissas: 1) a formulação de políticas sociais para combater a elevada pobreza abissal é um fato histórico e social de extrema importância numa perspectiva econômica, política simbólica; 2) estas políticas sociais estão indissociavelmente ligadas às desigualdades persistentes, à confirmação de um patamar de desemprego estrutural, à midiatização do campo político, à condição de alvitre de governos de cunho popular; 3) os anseios do combate à pobreza ensaiam uma ampliação da capacidade de consumo social de necessidades básicas, mas também estão relacionados a uma dimensão de sociabilidade, de compartilhamento de conhecimento ou manifestações de apropriação de informações socialmente úteis, pertinentes ao mercado de trabalho; 4) a proposição da dimensão compensatória parece responder tanto às demandas de manifestações populares e também corresponder às formas com que o Estado incorpora questões e enseja dependência dos setores empobrecidos; 5) uma investigação que tente análise comparativa enfrentará dificuldades com diferentes medições dos fenômenos sociais e que se dissemina pelo campo social, operando como um poderoso elemento de atualização da lógica das desigualdades; 6) as ações políticas em questão podem ser investigadas como mecanismos conectados a desdobramentos para robustecer o capital social dos trabalhadores (paradoxalmente ser sujeitos de direitos e da ação e qualificação tecnológica para obter rendimentos), onde a distribuição de renda é uma das formas de atestar da sua insuficiência para a inclusão social ou promoção social; 7) a condição da satisfação ou da insatisfação em face de necessidades constitui experiência de caráter individual, mas cuja fonte encontra-se na posição social dentro da organização da sociedade.

Na discussão do presente texto compartilhamos com a noção utilizada por González de la Rocha (2005, p. 81)

El capital social se realiza y manifiesta por medio de relaciones sociales... en cuanto recurso que puede ser activado para generar mayor riqueza, entendida esta como bienestar y éxito en los emprendimientos de los individuos, grupos o sociedades, teniendo en cuenta que dicho recurso no es solo material y tangible, sino que tiene componentes socioemocionales, como la autoestima, el reconocimiento y el ejercicio de influencia, autonomía, poder y control.

Assim, o problema central que orienta a reflexão pode ser desenvolvido a partir das seguintes questões: em que momento conjuntural as políticas sociais segmentadas e focalizadas são produzidas e por qual confluência de forças políticas ou interações sociais? De que modo as políticas de distribuição monetária e condicionada ensejam mecanismos para forjar uma apropriação de capital social diversificado e, portanto, além dos aspectos econômicos usualmente destacados, revelam indícios de superação de uma cultura da desqualificação social? Em que medida as políticas sociais conformam uma rede de proteção social, além da distribuição de um valor pecuniário, se existe em ação um conjunto de programas de promoção social com metas diferenciadas para atentar para a multiplicidade da vulnerabilidade em situação de desemprego estrutural?

$\mathrm{Na}$ investigação, os autores optaram pela utilização de uma dupla estratégia referente ao problema da metodologia para dar conta da questão de pesquisa com uma abordagem a partir da pesquisa documental e, ao mesmo tempo, valendo-se de uma intensa observação empírica ao nível local. O enfoque da pobreza e das políticas sociais fundamenta-se numa concepção da metodologia multidimensional que reflete o esforço de construção analítica dentro da reflexividade e da complexidade. 
Deste último aspecto, duas regiões de cada país foram destacadas: Cidade de León, com 1,5 milhões de habitantes, no estado de Guanajuato, região central do México, com observação das ações promovidas pelos chamados "enlaces" ou agentes locais e demais intermediários municipais; e região metropolitana de Porto Alegre, sul do Brasil, com cerca de 2,5 milhões de habitantes, com investigação das atividades realizadas ao nível local para dar efetividade ao programa. Ao mesmo tempo, os autores participaram, como coordenadores nacionais, de pesquisa internacional sobre "heterogeneidade das dimensões da pobreza e as políticas sociais em nações latino-americanas" envolvendo nove países e seus respectivos núcleos de investigação social.

Os autores se distanciam de um viés normativo para a sua compreensão e, ao mesmo tempo, endossam que a investigação e a análise das políticas sociais são fortemente condicionadas pela conjuntura (FARIA, 2005). Igualmente, se distanciam do olhar dos gestores estatais das políticas, nos diferentes níveis governamentais, bem como de agentes políticos interessados em conhecer projetos exitosos ou com preocupação primordial em aprimorar as estratégias de efetivação. Na condição de cientistas sociais, buscamos apreender os mecanismos de formulação, a conjuntura dos arranjos políticos, os procedimentos estratégicos empregados para atender universalmente a população considerada vulnerável.

\section{Programa Oportunidades no México: trajetória e características}

Os programas focalizados na realidade mexicana se formularam como uma resposta à pauperização conjuntural e crescente, produzida pela quebra do modelo articulado em torno de importação/exportação. Na trajetória se expressam, de forma evidente, várias crises sucessivas desde a década de 1980. Neste sentido, a persistência da pobreza carece de esforços interpretativos (MENDIZÁBAL, 2008), seja numa aproximação aos condicionantes locais, seja numa esfera mais ampla.

Ainda na primeira década do século 21, e sem diferenças expressivas entre os governos sobre a sua faceta subserviente na aplicação do modelo neoliberal, encontra-se, ao final de 2004, com a crise provavelmente conhecida como a mais severa em sua história centenária. Neste modelo prega-se o enxugamento e a eficiência da máquina estatal e são enfatizadas as políticas focais, portanto estacionam os recursos para políticas universais. A catástrofe ou passagem histórica ficou conhecida de forma coloquial como "o erro de dezembro", pois constrange o governo a suspender as estratégias da política social aplicada até então, cujo nome, por ironia de forma emblemática, foi "Solidaridad". O Banco do México fundamenta o severo programa de ajuste para enfrentar esta profunda crise com uma justificativa de racionalidade instrumental.

Com uma lógica distinta ao que havia sido impulsionado anteriormente, o programa eleito como bandeira do desenvolvimento social, o Progresa (Programa de Educación, Salud e Alimentación) anseia cortar o círculo vicioso da pobreza intergeracional e focaliza ainda mais a assistência social, aponta para o longo prazo e ensaia agir sobre o capital social (GONZÁLEZ DE LA ROCHA, 2005). Neste sentido, seleciona comunidades pobres e, mais ainda, a partir disso, detecta, de acordo com certos critérios muito discutidos, as famílias mais pobres com as respectivas desigualdades de oportunidades. Está visível o intuito de alterar a relação entre capital social e pobreza na medida em que se projeta que a maior presença do primeiro distancia da condição da segunda.

Na avaliação oficial na versão governamental, na acepção de Boltvinik e Damián (2007), um par de anos depois, o Progresa resultou satisfatório, pois o impacto em seu componente educativo indica que "las tasas de inscripción en primaria fueron 2.2 puntos porcentuales más altas" e "en secundaria si mostró que la captación de estudiantes subía 4.9\%" (PROGRESA, 1999, p. 167). Também se observou um crescimento na matrícula entre os beneficiários, modificações que são mais evidentes quando se trata de matrículas femininas.

Atualmente, em continuidade plena com as pautas aplicadas anteriormente, o programa emblema de combate à pobreza, denominado Oportunidades, se centra em estratégias para romper com as restrições que obstaculizam a acumulação de ativos humanos e financeiros. Isto significa o acesso às oportunidades produtivas como uma forma de romper com a pobreza intra e intergeracional. Por sua vez, Martínez (2012) ratifica os efeitos das transferências como forma de bolsa para a educação sobre a frequência assiduidade escolar.

O eixo e fluxo Progresa/Oportunidades consolidou-se como fio condutor da política social focalizada e condicionada por mais de uma década. Entre os desafios dos programas de transferências monetárias, situa-se a pretensão de subvenções como benefícios, ao mesmo tempo em que há custos sociais e busca de legitimação.

A partir de 2010, o Programa Oportunidades alarga ainda mais o espectro de operação assistencial com o Programa de Apoyo Alimentario (PAL). Durante a presente década, emergiram vários programas de alento ou supostamente benefícios à população focalizada. Entre as dimensões agregadas pelas mudanças as mais importantes tem sido: a) a cobertura que o programa alcançou cerca de seis milhões de famílias; b) o programa 
de apoio alimentar "Vivir Mejor" aspira amenizar o impacto inflacionário; c) auxílio infantil "Vivir Mejor" para crianças de até nove anos de famílias cadastradas; e d) as transferências por meio do "70 e más", para pessoas da terceira idade que vivem em povoados com menos de 30 mil habitantes.

As modificações recentes realizadas no programa Oportunidades, em termos de modalidades e de montantes, não têm alterado o modelo, ao mesmo tempo em que tais adições foram engendradas, porém sem base em diagnóstico (CONEVAL, 2011). Isto se pode interpretar como uma tentativa de responder à conjuntura proporcionada pela crise econômica do ano de 2009 e seu impacto negativo sobre a população mais empobrecida em face das restrições de acesso à cesta básica de alimentos.

\section{Programa Bolsa Família em terras brasileiras: trajetória e características}

O debate sobre as questões sociais e seu financiamento em países da América Latina contemporânea insta à contextualização histórica das circunstâncias do quadro de possibilidades e de restrições macroeconômicas no cenário do país: o esgotamento do modelo de desenvolvimento propriamente nacional ou desnacionalização, o fenômeno das diferenças na balança comercial, o endividamento e o impacto da dívida pública interna e externa, o processo de desindustrialização, a extensão do desemprego estrutural, a financeirização da economia e o colapso fiscal-financeiro do Estado nacional.

Um breve retrospecto histórico do sistema de proteção social no Brasil e considerações sobre o contexto econômico e político parecem relevantes para compreender os modelos de políticas sociais em tensão no qual se confrontam as tendências universalistas e focalizadoras (KERSTENETZKY, 2009; COBO; LAVINAS, 2010). Os anos 1980 caracterizam-se pelas lutas da sociedade por direitos sociais universais, com garantias de participação em processos decisórios e cuja trajetória demarcou a nova Constituição do país em 1988. Porém, a sua concretização entrou em rota de colisão com os arranjos políticos nos anos subsequentes. A tensão como pano de fundo já se fazia presente entre universalização - com políticas mirando a longo prazo e acesso indistintamente - e focalização - tratamento em situações emergenciais de privação com caráter seletivo (na lógica da discriminação positiva ou, noutro viés, na criminalização da pobreza). Esta última ênfase passou a ampliar sua projeção no cenário político ao longo de duas décadas com as políticas focais ou programas de transferência de renda (MEDEIROS; BRITTO; SOARES, 2007). São dois projetos em disputa: um impulsionado ao longo dos anos 1980 por uma vertente política popular-democrática de cunho universalista; e outro de políticas sociais focalizadas ou de ótica compensatória, bem a gosto do estilo neoliberal, incorporando conceitos como eficácia dos gastos públicos, produtividade e rendimento, individualização, vulnerabilidades, regulação social, benefícios em lugar de direitos.

Nas origens da experiência de políticas sociais focalizadas, encontramos antecedentes de uma prática de relação entre Estado e população pobre que remonta, ao menos desde os anos 1980, com a distribuição de alimentos ou subsídios alimentares como medidas compensatórias para minorar a pobreza. Na realidade, encontram-se os elementos históricos da passagem da distribuição em espécie de gêneros de primeiras necessidades, como os alimentícios, entre outros, bem como da lógica assistencialista (da ação assistencial, das campanhas, bolsas e auxílios diretos etc.) para o campo de políticas sociais sob a responsabilidade do Estado.

No auspicioso propósito político de erradicar a pobreza e a fome secular e de minimizar as desigualdades, desponta uma nova retórica compreendendo-as como iniquidades históricas e desigualdades proeminentes nas sociedades latino-americanas (VALENCIA LOMELÍ, 2008; DRAIBE; RIESCO, 2009). Algumas breves referências aos antecedentes históricos da longa trajetória das políticas sociais no Brasil são feitas, em particular o Programa Bolsa Família (PBF), pois resulta fundamental aproximar-se de suas orientações durante duas décadas e as respectivas transformações. Dialogando com outras vertentes para construção crítica do processo analítico, Rego (2008, p. 173) enfatiza o longo processo de desconstrução do conservadorismo e a chegada tardia de políticas sociais, a propósito do processo de modernização do século 20.

[...] os programas sociais do governo atual chegaram muito tarde. O sofrimento social e politicamente evitável de milhões de brasileiros faz parte de nossa paisagem como coletividade humana. Sua enormidade e iniquidade são constitutivas de nossa formação como Estado-Nação. Desde então permanece jogando sua sombria realidade sobre os desdobramentos futuros do país. A industrialização e consequente modernização no século XX foram realizadas sem nenhuma política, digna deste nome, de justiça distributiva.

A abordagem pode caracterizar o PBF como uma inovação em comparação aos programas sociais de transferência de renda anteriores, como as medidas criadas no governo de Fernando Henrique Cardoso (19942002). Existem possíveis continuidades e rupturas, notadamente nas políticas de combate à pobreza, entre os 
governos brasileiros, em matéria de política social entre 1994-2010: o Programa Comunidade Solidária, no governo de Fernando Henrique Cardoso; e o Programa Bolsa Família, na gestão do presidente Lula (TESSAROLO; KROHLING, 2011).

Setores da sociedade civil já haviam encaminhado, nos anos 1990, um conjunto de medidas para uma Política de Segurança Alimentar de forma a subsidiar a elaboração do Plano Nacional de Combate à Fome e à Miséria, além da criação do Conselho Nacional de Segurança Alimentar (Consea). Este movimento de dimensão nacional se denominava de "Ação da Cidadania contra a Fome, a Miséria e pela Vida", inspirado em razões de ordem ética e no destaque à solidariedade. Sob a liderança do sociólogo Herbert de Souza, desencadeia a Campanha contra a Fome e a Política Nacional de Segurança Alimentar.

Os condicionantes e a focalização significaram uma soma de esforços para o fortalecimento de políticas públicas na direção da universalização efetiva, ao mesmo tempo com nuanças restritivas de gastos públicos e adequação ao ajuste fiscal (DRUCK; FILGUEIRAS, 2007; KERSTENETZKY, 2009). O PBF institui um passo para a constituição das políticas de proteção social, em sua controvérsia com os direitos de assistência social e a institucionalização da política de renda mínima. A experiência se aprimora e se aprofunda depois da virada do milênio, por meio de projetos sociais e mudança de enfoque com distribuição monetária.

O planejamento e a articulação da assistência social,

Ao abordar semelhanças e

diferenças recentes parecem

destacar-se a diversificação de

programas, o similar desfecho

e circunstância política, os

instrumentos de avaliação do

desempenho e os efeitos

potenciais a partir da alteração

de indicadores sociais. em preparação à gestão de um novo mandato presidencial, estacam-se pelas peculiares características na formulação do Programa Fome Zero, cuja estratégia se compunha de políticas emergenciais, transversais e estruturantes: uma política de segurança nutricional e alimentar; a criação de conselhos gestores nos três níveis; banco de alimentos, entre outros. Tratava-se de uma compreensão abrangente de proteção e de assistência social a partir das persistentes desigualdades, da pobreza e da exclusão social. O plano estratégico deste programa previa quatro eixos articuladores das ações: acesso a alimentos, fortalecimento da agricultura familiar, geração de renda, articulação e mobilização e controle social (como é o caso do Consea). O cenário do país em desenvolvimento enseja desafios imensos, como demonstravam as contradições sociais evidentes pela existência de milhões de brasileiros despossuídos de trabalho, de capacitação profissional, de propriedade e renda, sobrevivendo na insegurança social.

A ação do PBF está centrada num sistema de proteção social com previsão de estratégias políticas complementares sob quatro aspectos: focalização, transversalidade, intersetoriedade e planejamento. Entram nesse cenário, de acordo com Medeiros, Britto e Soares (2007), as políticas de transferência de renda que têm por característica: a seleção de público-alvo, a focalização da política a ser implantada, a atribuição de cumprimento de condicionalidades aos beneficiários para permanência no programa e distribuição direta de recursos financeiros.

A proposta do PBF possui uma grande tensão interna, pois, de certa forma, enseja o universal e uma dimensão focal (KERSTENETZKY, 2009; LAVINAS, 2012; COBO; LAVINAS, 2010). Almeja-se reduzir a pobreza universalizando o acesso aos programas sociais a todos os municípios brasileiros, iniciando a ação pelos mais pobres e estendendo-a aos demais. Contudo, também revela características muito marcantes de focalização, por voltar-se à demanda dos mais pobres, uma parcela específica da população.

Em algumas circunstâncias, se destaca a presença da autosseleção, como em situações de famílias muito pobres e/ou em localidades distantes de centros urbanos: dados os custos privados e sociais em participar do programa. De um lado, os indivíduos mais necessitados teriam mais motivos para inscrever-se na política, de outro também estão os que tendem a enfrentar mais obstáculos.

\section{Impacto das políticas sociais compensatórias ou transferência condicionada}

A investigação comparativa não se pauta por abordar os casos mais contrastantes, ao contrário, embora as possíveis divergências nacionais, enfatiza os caminhos convergentes em políticas sociais de tipo compensatório ou focal relacionado com a mitigação da fome. Ao mesmo tempo discorda da busca de uma uniformidade das trajetórias de mudança ou de desenvolvimento social, pois a utilidade de uma ferramenta comparativa se debruça sobre as convergências em políticas sociais, sem descuidar da pluralidade das formas sociais ou 
conjunturais. A presente análise afasta-se de certo contágio entre alguns intérpretes da questão do combate à pobreza, próximos da esfera administrativa, a qual gerou certo consenso em torno de vantagens do sistema de proteção social focal, sendo entendido mais do que um complemento das políticas de renda básica ou de encaminhamentos universais de cidadania.

Uma das principais preocupações deste texto consiste em destacar a ratificação do acordo sobre o que e como formatar a visão sobre as políticas sociais de transferências condicionadas no que diz respeito ao marco de definição metodológico-teórica em um contexto de arranjos políticos. Sob a baliza da economia política, examina-se, em particular, a decisão política sobre a expansão de políticas sociais num momento de estancamento fiscal, entre outros dissabores (DRUCK; FILGUEIRAS, 2007). Estas dimensões prevaleceram nos países da América Latina enquanto também explicitam as circunstâncias do impacto positivo, negativo ou limitado dos programas de mitigação da pobreza extrema por meio de transferências condicionadas.

\subsection{Contribuição de oportunidades em seus próprios termos diante da pobreza}

Entre 2004 e 2007, se incrementou inovações de avaliação para enveredar por uma adequação sobre sua influência em face da redução da pobreza. A criação do Conselho Nacional de Avaliação da Política de Desenvolvimento Social (Coneval) ocorreu em 2006. Este órgão, ligado à Sedesol, está integrado por seis investigadores com as seguintes atribuições: a) medição da pobreza multidimensional em nível nacional, estadual e municipal a partir da vigência de critérios unificados de medição; b) normatizar e coordenar os processos de avaliação de programas e políticas da área de desenvolvimento social (CONEVAL, 2011).

Torna-se igualmente relevante diferenciar impacto específico das transferências condicionadas dos demais programas sociais. Dito de outro modo, seria injusto atribuir ao Oportunidades a responsabilidade exclusiva de alterar a persistência e a trajetória da pobreza na sociedade mexicana, seja ao nível local ou no âmbito nacional (MENDIZÁBAL, 2008). As práticas de gestão, de acordo com Grau e Bozzi (2008), se traduziram em condições para o fortalecimento de sistemas em aprimoramento para o monitoramento do desempenho e avaliação dos seus efeitos na América Latina (VALENCIA LOMELÍ, 2008; DRAIBE; RIESCO, 2009).

Existem, na literatura ou nas fontes documentais acessadas na elaboração do presente texto sobre a avaliação de Oportunidades, ao menos duas fontes de informação cujo fato parece conveniente considerar: a avaliação "externa", que se realiza por meio de um grupo que se contrata com propósito específico por parte da Sedesol-Coneval; e a avaliação de acordo com este último se estabelece pela tipologia com relação ao diagnóstico a realizar-se por meio do impacto, dos processos, dos indicadores, da consistência, entre outros resultados (GRAU; BOZZI, 2008).

A partir do esforço para introduzir uma maior segurança na qualidade das avaliações em políticas governamentais, de acordo com o Coneval (2011), considera-se como os principais baluartes ou fatores da solidez do Programa Oportunidades: a) $\mathrm{O}$ atendimento à pobreza de uma maneira integral, atacando as causas estruturais, como o baixo investimento em capital humano; b) $\mathrm{O}$ fomento da corresponsabilidade dos beneficiários; c) Os impactos de curto e largo prazo sobre nutrição, saúde e educação decorrentes dos apoios complementares; d) a quantidade de informações e avaliações sobre uma multiplicidade de aspectos fundamenta a inversão em qualificação visando o mercado de trabalho; e) A continuidade de 14 anos; aspecto fundamental para inversão em capital humano.

O balanço demonstrado, por meio dos resultados quantitativos da política social, possui dois ramos de análise. Por uma parte, os resultados expressos mostram claramente as alterações no âmbito da pobreza multidimensional, cuja abordagem foi eleita por mandato da Lei de Desenvolvimento Social de 2004 e posta em prática três anos depois compreendendo igualmente os programas na dimensão multidimensional. Por sua vez, Boltvinik (2010, p. 45) destaca oito princípios a considerar para uma abordagem dimensional e justifica tal convicção porque "la medición multidimensional de la pobreza enfrenta (entre otros) el problema de la heterogeneidad aparente entre dimensiones del bien-estar, lo que se deriva de la multiplicidade de las necesidades humanas, satisfactores y fuentes de bien-estar".

Os indicadores de educação, saúde, alimentação e seguridade social obtiveram uma trajetória ascendente em termos de combate ao atraso histórico. Para 2010, a média da população mexicana está com maior atendimento à saúde, pois se expandiram horizontalmente os serviços médicos, aumentou a escolarização e há menos problemas na cobertura de serviços públicos de água potável, de energia elétrica ou habitacional.

Uma das vertentes do paradigma, onde se assentam os principais argumentos da base conceitual de Oportunidades, prescinde de colocar adequadamente o comportamento do mercado; particularmente a oferta real na estrutura de ensejos como uma condição para que as competências e capacidades decorrentes da política social atinjam um elemento objetivo do seu florescimento. A compreensão e as ações transcorrem como se a estrutura 
de oportunidades para mover os pobres estivessem dadas ou a população esperando com os braços abertos os magos para elevar seu nível de saúde, educação e alimentação como um sucesso extemporâneo.

A política social deve conter uma mínima congruência entre a postura pública sobre o bem-estar e os riscos sociais e, no caso mexicano, pode-se afirmar que entre ambas existe uma manifesta inadequação. Salta aos olhos do observador atento em face dos desdobramentos locais que nas circunstâncias de crianças e jovens permanecem profundas desigualdades quanto às oportunidades educacionais (MARTELETO; CARVALHAES; HUBERT, 2012).

\subsection{Sutis resultados de bem-estar na contribuição polêmica do PBF}

As políticas sociais transmutaram-se em processos sociais relevantes para o enfrentamento da pobreza, porém, com a gestão opera-se, em outros termos, o financiamento público das atividades assistenciais e mitigadoras das vulnerabilidades. Além de aliviar a pobreza no curto prazo, por meio da transferência direta de renda, a política social focalizada depara-se com obstáculos amplos e diversos para alterar estruturalmente a situação socioeconômica e interromper a perpetuação da pobreza. As investigações feitas no Brasil pelas ciências sociais dão suporte a estas especulações.

As políticas de Transferência Condicionada de Renda (TCR) se fazem sentir para superar as ações emergenciais e assemelhar-se a programas estruturais. Para além da distribuição monetária, o fim da miséria centra-se no combate à insuficiência de capital social. Além do repasse monetário, outro patamar de informação, de relacionamentos e de conhecimento para uma inserção qualificada no mercado de trabalho. No entanto, a maioria da população beneficiária não se caracteriza por estar sem atividade remunerada ou fora do mercado de trabalho, talvez antes uma inserção pendular. Estas medidas estruturantes de modificação do horizonte cultural tendem a ser mais complexas do que a organização da distribuição monetária. Todavia, além destas dimensões, outras comparecem com igual importância: o direito à segurança alimentar, à habitação, à água potável e ao saneamento.

As diversas ênfases metodológicas na abordagem das políticas sociais, com os seus respectivos pressupostos, podem oferecer também resultados diversificados. A metodologia qualitativa ou participativa de aferição dos resultados - com o crescente reconhecimento da sua crítica ou enquanto inventividade de "empoderamento" - considera sistematicamente a ótica e as expectativas dos beneficiários. Tal apreciação dos resultados pode apresentar-se como informações relevantes para a reformulação das políticas. Esta perspectiva distancia-se, é importante frisar, da abordagem neo-institucional e da visão gerencial do Estado, que enfatiza resultados em detrimento dos processos, portanto, onde se prima pela satisfação dos "clientes" ou dos beneficiários mitigados em sua escassez.

Do ponto de vista econômico, as diversas investigações empíricas, com seus períodos de abrangência e metodologias diferentes, atestam resultados, seja referente à extensão, sejam indícios relativos à contribuição para a queda da pobreza numa perspectiva conjuntural decorrente de seu grande impacto (HELFAND; ROCHA; VINHAIS, 2009). Todavia, menos sobre a redução das persistentes desigualdades da realidade brasileira, onde ele se situa entre outros componentes que contribuíram como a renda do trabalho e as pensões e aposentadorias vinculadas ao salário mínimo. Considerando que a maioria dos familiares se encontra no trabalho informal ou no desemprego, de um lado existe uma débil confirmação exata da renda total das famílias beneficiadas, e de outro uma sóbria transferência monetária pode resultar em impacto destacado sobre a pobreza e a fome.

Do ponto de vista político, se põe de forma mais ou menos clara a produção da legitimação política. Apesar das críticas relacionadas ao uso político-eleitoral do programa (MOURA, 2007), o grau de focalização, vigor e legitimidade do PBF na redução da pobreza e das desigualdades sociais são pontos reconhecidos por diversos estudos. A abordagem do impacto distributivo das políticas sociais focalizadas apenas pelo ângulo monetário ou dos gastos são insuficientes devido à complexidade da pobreza multidimensional. Para considerar adequadamente os impactos sociais dos gastos públicos na área da proteção social convém associá-los com a dimensão crucial de efetividade e eficácia distributivas.

Do ponto de vista social, é bem compreensível que as condicionalidades potencialmente influenciarão previsivelmente uma mudança nas gerações futuras (educação dos filhos) e de suas competências para o mercado de trabalho. Neste campo, os impactos a respeito de tais variáveis sem dúvida poderão ser razoavelmente mensurados após um ciclo escolar completo (MEDEIROS; BRITTO; SOARES, 2007). Todavia, as transferências monetárias de caráter assistencial ou proteção, ao mitigar a questão social por meio do processo distributivo, ainda que possam servir como estratégia direta de combate à pobreza, parecem distantes de constituírem solução estrutural para o problema das desigualdades. 


\section{Da análise comparativa: algumas considerações finais}

As reestruturações econômicas conduziram à experimentação de distintos modelos focalizadores de política social, que se inseriram pouco a pouco, desde a década dos anos 1990, sendo que em seus alcances ordinariamente articulam-se com políticas pretensamente de alcance universal. Esta articulação vem apresentando variações ao longo do período, no quesito da eficiência, e permitiu diminuir os alijamentos específicos (educação, saúde, alimentação, moradia e outros serviços públicos), ainda que a uma velocidade e eficácia intermitente. As transferências monetárias diretas aos cidadãos adquiriram legitimidade nacional como política de Estado para atenuar as crises diversas; sobretudo as de 1994, 2002 e 2008/2009, no caso do México, e provocaram a incorporação de milhões de pessoas aos limiares de pobreza nunca observados na história recente dos países. Ainda há que acrescer, além destes aspectos, que sem dúvida a atenção aos setores populacionais excluídos tem seu fundamento último em um enfoque de direitos de cidadania e não na concessão assistencial e voluntarista de governos.

Deste ponto de vista, temos dois pontos a destacar: a) Originalmente a formulação do Programa Oportunidades se desenhou para combater a pobreza intergeracional, porém, no curso do tempo, foi se tornando somente mais um programa de combate à pobreza. Ainda mais que, de fato, abarca apenas a metade da gente pobre no México e se somam adversidades para chegar aos territórios de pobreza extrema; b) Devido as suas contingências o programa ficou aquém do pretendido, pois se apresentou incapaz de lograr seus propósitos no que diz respeito ao impulso de políticas de geração de empregos, com políticas estratégicas de qualificação para a geração de capacidades visando trabalho e, concomitantemente, a elevação da renda familiar. De fato, neste período, os cidadãos obtiveram maior acesso e mais saúde e escolaridade, porém igualmente cresceram as restrições no encalço de inserção no mercado de trabalho.

As investigações acadêmicas ou governamentais ou consultorias externas sobre o tema das políticas sociais de transferência condicionada de renda são parcimoniosas no quesito que diz respeito ao impacto do acréscimo de renda como impulsionador do retorno ou inserção mais qualificada no mercado de trabalho. Haveria uma redução da presença no mercado de trabalho em consequência direta do aumento da renda pela transferência monetária?

Em termos comparativos persiste nos dois países um sistema de informação com método e critérios de seleção a partir de um banco de dados. No caso mexicano, no processo de seleção e de incorporação se aplica um complexo sistema de pontuação referente aos distintos aspectos de bem-estar, bem além do critério da renda familiar e da presença de menores de idade, como no caso brasileiro. Todavia, em ambos os casos existe uma generosa evolução ou expansão considerando a ampliação do volume de famílias incorporadas aos mecanismos de transferência monetária.

$\mathrm{O}$ tema das condicionalidades em meio aos acadêmicos mantem-se amplamente controverso entre os estudiosos de políticas sociais e do significado dos desdobramentos históricos dos direitos de cidadania. A operacionalização das condicionalidades aproxima do acesso às políticas públicas, com acesso a alguns direitos fundamentais e oportunidades futuras, porém a transferência de renda não converte em direitos aos benefícios. No que diz respeito à educação (frequência escolar de crianças e jovens) e à saúde (consultas, vacinas, acompanhamento), as exigências, como contrapartida, se apresentam similares no Brasil e no México. Assim, em mais de uma década de vigência incidem sobre o nível educacional e a ampliação da cobertura do sistema de saúde, seguridade e proteção social. Ocasionalmente podem ser organizados trabalhos comunitários ou de serviços urbanos. No México, há algumas distinções: a assistência às práticas de saúde, que consiste de um encontro mensal para troca de informações a respeito do cuidado à vida saudável; o suplemento alimentar a menores e mulheres em condições peculiares; a atribuição de bolsas de valor diferenciado para crianças e adolescentes progressivo de acordo com o nível educacional e de gênero.

No período da vigência das políticas em exame, as desigualdades tiveram queda quase irrelevante nos dois países, apesar das promessas em contrário, representam um indicador relativo à queda da pobreza. Em ambos os casos, as evidencias de pesquisas empíricas e como programas similares, os Programas PBF e Oportunidades, apontam reduzido impacto sobre a oferta de trabalho aos beneficiários. Em outros termos, deixam lacunas enquanto política inclusiva de alargamento da qualificação dos beneficiários e, como tal, acesso ao mercado de trabalho, especialmente os jovens. Em sua formulação, aludem, porém não produzem os mecanismos práticos para a construção e requalificação do capital social com a meta de alavancar a renda para nova inserção no mercado de trabalho e, assim, romper com a reprodução da persistente pobreza.

A diferença substantiva quanto aos resultados entre Oportunidades e Bolsa Família refere-se ao esforço alcançado no cenário brasileiro repercutindo na elevação da renda real das famílias; ou seja, o seu poder de compra com expansão do consumo de alimentos e outros bens cotidianos. No México verifica-se a ausência de uma macropolítica a este respeito, bem como a inflação ou carência de alimentos tem sido um dos fatores 
relevantes para a manutenção ou mesmo elevação da pobreza. Desta forma, portanto, a política da gestão das transferências monetárias condicionadas se delimita às estratégias de administrar os níveis de pobreza ao invés de tentar erradicá-la.

Por fim, cabe anotar a larga inconveniência quando a política social pode estar direcionada exclusivamente centrada no combate à pobreza como carência material. Os seus objetivos profundos e seus resultados alentadores encontram-se em outras esferas: o logro da restituição do tecido social, a mitigação da desigualdade, o alargamento de capacidades ou competências quanto ao capital social e a busca de bemestar com cidadania.

\section{Referências}

BOLTVINIK, J.; DAMIÁN, A. (Ed.). La pobreza en México y el mundo. Realidades y Desafíos. México: Siglo XXI. 2004.

BOLTVINIK, J. Principios de medición multidimensional de la pobreza. La Sociología en sus escenarios. Revista La Sociología en sus escenarios, Medellín, Colombia, n. 21, p. 36-55, 2010.

COBO, B.; LAVINAS, L. Políticas sociais universais e incondicionais: há chances reais de sua adoção na América Latina? 2010. In: $13^{\circ}$ CONGRESSO INTERNACIONAL DA REDE MUNDIAL DE RENDA BÁSICA - BIEN. 30 jun. a 2 jul. São Paulo: USP, 2010.

CONEVAL - Consejo Nacional de Evaluación la Política de Desarrollo Social. Informe de la Evaluación Específica de Desempeño 20102011. Programa de Desarrollo Humano Oportunidades. Coordinación Nacional del Programa de Desarrollo Humano Oportunidades. Coneval, 2011.

DRAIBE, S. M.; RIESCO, M. El estado de bienestar social en América Latina: una nueva estrategia de desarrollo. Documento de trabajo n. 31. Fundación Carolina-CeALCI, Madrid, España. 2009. Disponible en: <http://www.fundacioncarolina.es/es-ES/publicaciones/ documentostrabajo/Documents/DT31.pdf>. Acceso en: 5 jun. 2013.

DRUCK, G.; FILGUEIRAS, L. Política social focalizada e ajuste fiscal: as duas faces do governo Lula. Revista katálysis, Florianópolis: Edufsc, v. 10, n. 1, p. 24-34, 2007. Disponível em: <https://periodicos.ufsc.br/index.php/katalysis/article/view/1199/7328>. Acesso em: 5 jun. 2013.

FARIA, C. A. P. A política da avaliação de políticas públicas. Revista Brasileira de Ciências Sociais, Anpocs, São Paulo, n. 59, p. $97-$ $109,2005$.

GONZÁLEZ DE LA ROCHA, M. México: Oportunidades y capital social. In: ARRIAGADA, I. (Ed.). Aprender de la experiencia. El capital social en la superación de la pobreza. Santiago de Chile: Cepal, 2005.

GRAU, N. C.; BOZZI, O. S. Fortalecimento dos Sistemas de Monitoramento e Avaliação (M\&A) na América Latina. Informe Comparativo de 12 países. Natal, RN: Searh, 2008.

HELFAND, S. M.; ROCHA, R.; VINHAIS, H. E. F. Pobreza e desigualdade de renda no Brasil rural: uma análise da queda recente. Pesquisa e Planejamento Econômico - PPE, v. 39, n. 1, abr. 2009.

KERSTENETZKY, C. L. Redistribuição e desenvolvimento? A economia política do Programa Bolsa Família. Dados - Revista de Ciências Sociais, Rio de Janeiro, v. 52, n. 1, p. 53-83, 2009.

LAVINAS, L. Brasil, de la reducción de la pobreza al compromiso de erradicar la miséria. Revista CIDOB d'afers internacionals, España, n. 97-98, p. 67-86, 2012.

MARTELETO, L. J.; CARVALHAES, F.; HUBERT, C. Desigualdades de oportunidades educacionais dos adolescentes no Brasil e no México. Revista Brasileira de Estudos Populacionais, São Paulo, v. 29, n. 2, p. 277-302, 2012.

MARTÍNEZ, O. A. M. Efectos de las becas educativas del programa Oportunidades sobre la asistencia escolar. El caso de la zona urbana del noreste de México. Revista Desarrollo y Sociedad, Bogotá, n. 69, p. 99-131, 2012.

MEDEIROS, M.; BRITTO, T.; SOARES, F. Transferência de renda no Brasil. Novos Estudos - Cebrap, São Paulo, n. 79, p. 5-21, 2007. MENDIZÁBAL, D. M. Política social y pobreza en Guanajuato. Reconstrucción de una trayectoria local útil para las entidades federativas. León: UIA; Editorial Aportes, 2008.

MOURA, P. G. M. de. Bolsa Família: projeto social ou marketing político? Revista Katálysis, Florianópolis: Edufsc, v. 10, n. 1, p. 115122, 2007. Disponível em: <https://periodicos.ufsc.br/index.php/katalysis/article/view/1284/7337>. Acesso em: 5 jun. 2013.

PROGRESA-Programa de Educación, Salud y Alimentación. Más oportunidades para las familias pobres. Evaluación de resultados del Programa de Educación, Salud y Ali-mentación. Primeros avances, México, 1999.

REGO, Walquiria L. Aspectos teóricos das políticas de cidadania: uma aproximação ao Bolsa Família. Lua Nova, São Paulo, n.73, p. 147-185, 2008.

TESSAROLO, E. M.; KROHLING, A. A passagem do Programa Comunidade Solidária para o Programa Bolsa Família: continuidades e rupturas. CAOS - Revista Eletrônica de Ciências Sociais, João Pessoa, n. 17, p. 74-92, 2011.

VALENCIA LOMELÍ, E. Las transferencias monetarias condicionadas como política social en América Latina. Un Balance: Aportes, Límites y Debates. Annual Review of Sociology, v. 34, p. 499-524, 2008. 


\section{Aloisio Ruscheinsky}

aloisior@unisinos.br

Doutor em Sociologia pela Universidade de São Paulo (USP)

Professor do Programa de Pós-Graduação em Ciências Sociais da Universidade do Vale do Rio dos Sinos (Unisinos)

\section{Unisinos}

Avenida Unisinos, 950

São Leopoldo - Rio Grande do Sul - Brasil

CEP: 93022-900

\section{David Martínez Mendizábal}

david.martinez@leon.uia.mx

Doutor em Ciencias Sociales pela Universidad Jesuita de Guadalajara (Iteso)

Professor do Departamento de Ciencias Sociales y Humanidades da Universidad Iberoamericana (UIA) León, México

\section{UIA}

Blvd. Jorge Vertiz Campero, 1640

Col. Cañada de Alfaro

León - Guanajuato - México

C. P. 37238 